\title{
Age dependency in neophobia: Its influence on taste-aversion learning and the flavor-preexposure effect in rats
}

\author{
JAMES R. MISANIN and LOUIS A. BLATT \\ Susquehanna University, Selinsgrove, Pennsylvania \\ and \\ CHARLES F. HINDERLITER \\ University of Pittsburgh at Johnstown, Johnstown, Pennsylvania
}

\begin{abstract}
Five experiments were conducted to evaluate various aspects of stimulus preexposure effects on conditioned saccharin aversion in rats of three age groups: weanling (19-25 days), young-adult (92-170 days), and old-age (680-850 days). In Experiment 1, flavor neophobia was examined. Only the young-adult and old-age animals showed evidence of neophobia. Furthermore, habituation of the neophobic reaction differed for these two age groups. Using a brief to moderately long flavorpreexposure period and an intense US (Experiment 2), we demonstrated that the youngest age group was most likely to exhibit retarded conditioning as a result of preexposure to the flavor CS. Using a weaker US and a moderately long saccharin-preexposure period (Experiment 3), age differences in conditioning resulting from preexposure to the flavor CS were reduced. When animals were preexposed to saccharin continuously for $48 \mathrm{~h}$ (Experiment 4), age differences in the preexposure effect were not evident. In Experiment 5, the intensity of the US was reduced to determine whether floor effects in the previous experiments had masked age differences in the ability of nonpreexposed rats to acquire an aversion to saccharin. Results indicated that tasteaversion learning was directly related to age. Although open to other interpretations, the results support the notion that the flavor-preexposure effect is influenced by the initial level of flavor neophobia. They also suggest that systematic parametric variation is sometimes necessary to obtain an accurate description of age differences in learning.
\end{abstract}

Nonreinforced preexposure to a stimulus decreases the chances of that stimulus's becoming a conditioned stimulus (CS) when subsequently paired with an unconditioned stimulus (US). This preexposure effect has been demonstrated for a variety of stimuli, for a number of species, and in different learning situations (Lubow, 1973), and has been termed latent inhibition (Lubow \& Moore, 1959). Recently, Misanin, Guanowsky, and Riccio (1983) have suggested that when the preexposed stimulus is flavor and the learning situation is taste-aversion conditioning, this effect might vary with age. More specifically, they suggested that the ease with which flavor is established as a latent inhibitor or "safe" stimulus (Kalat \& Rozin, 1973 ) is inversely related to age. They found that three 30-min preexposures to saccharin prevented an aversion from being conditioned to saccharin in weanling rats but only retarded taste-aversion conditioning in young adult rats. They also found that weanling rats did not display neophobia when first exposed to a flavor, whereas young

This research was supported by a summer research grant from Susquehanna University to James R. Misanin. Reprint requests should be sent to James R. Misanin, Department of Psychology, Susquehanna University, Selinsgrove, PA 17870. adult rats did. Therefore, they suggested that, just as it is more difficult to convert a conditioned inhibitor than a neutral stimulus into a CS in excitatory learning, it should be more difficult to convert a feared stimulus than a neutral stimulus into a "safety" signal.

If flavor neophobia is age-dependent, and if the effectiveness of flavor preexposure in retarding taste-aversion conditioning is related to the strength of the neophobic reaction, then one can make several predictions: (1) With a brief preexposure period and an intense US, the flavorpreexposure effect should be evident in young rats but not in adults. A brief preexposure to the flavor should result in little habituation of the neophobic reaction in adult rats and the intense US should counteract any effect of habituation that did take place. In contrast, for the younger rats, even a brief preexposure to a neutral stimulus should provide sufficient experience to establish learned safety. (2) With moderately long preexposure and a weak US, age differences in the flavor-preexposure effect should diminish. Preexposure, in this case, should lead to substantial habituation of the neophobic reaction in older animals (at least in young adults), and the effect of habituation should not be counteracted by the weak US. (3) With a prolonged preexposure session, age differences 
in the effect of flavor preexposure on conditioning should disappear. All age groups should exhibit learned safety. (4) Just as it should be more difficult to convert a feared stimulus than a neutral stimulus into a "safety" signal, it should be more difficult to condition an aversion to a neutral stimulus than to a stimulus that is potentially dangerous. Thus, taste-aversion learning should be directly related to age in the rat. Although this latter prediction has been demonstrated to hold for a very narrow age range, weanling to young adult (Baker, Baker, \& Kesner, 1977; Martin \& Timmins, 1980), it has not been demonstrated for rats along the entire age continuum.

The purpose of the present series of experiments was to test predictions using weanling, young-adult, and oldage rats.

\section{EXPERIMENT 1}

The purpose of Experiment 1 was to replicate the findings of age dependency in the flavor neophobia of weanling and young adult rats (Misanin et al., 1983), and to see if this dependency extended to rats at the upper end of the age continuum. It was predicted that old-age rats should show the strongest neophobic reaction.

\section{Method}

Subjects. Sixteen 22-24-day-old (weanling), 16 101-104-day-old (young-adult), and 16 740-850-day-old (old-age) female albino rats were the subjects of this experiment. All rats were born and reared in the university animal colony. The animals were housed in pairs (one experimental and one control animal) in standard suspended galvanized rodent cages, and the animal colony was maintained on a 14-h-light/10-h-dark cycle. The rats had free access to food at all times except during the 30 -min drinking sessions. During the course of the experiment, one old-age rat developed a middle-ear infection and was discarded.

Apparatus. All 30-min drinking sessions took place in drinking cages that were identical to the home cages except that they had spring-grip clamps attached to the center and sides of the front of the cage to hold $100-\mathrm{ml}$ cylinders equipped with rubber stoppers and stainless steel sipper tubes. Throughout the course of this experiment, the cylinders were attached to the center of the front of the cage.

Procedure. Following $19 \mathrm{~h}$ of water deprivation, all rats were given two daily adaptation sessions, during which they had $30-\mathrm{min}$ access to room-temperature $\left(24^{\circ} \mathrm{C}\right)$ tap water in the drinking cages. Two and a half hours after these sessions, the animals were given 2 - $h$ access to water in their home cages. Following these adaptation sessions, the control animals at each age level were given nine daily drinking sessions in the drinking cages, during which they had $30-\mathrm{min}$ access to $.1 \%$ saccharin ( $\mathrm{w} / \mathrm{v}$ in tap water) solution to establish a saccharin-drinking baseline in the absence of flavor neophobia. The experimental animals at each age level were given nine daily drinking sessions in the drinking cages during which they had access to room-temperature tap water. Two and a half hours after each of these drinking sessions and the following test sessions, the animals were given 2 -h access to room-temperature tap water in their home cages. On each of the 3 following days all animals were given 30-min access to the saccharin solution in the drinking cages (test for flavor neophobia in experimental subjects). For all drinking sessions, the amount of fluid consumed by each rat during the first $20 \mathrm{~min}$ of the session and during the entire $30 \mathrm{~min}$ was recorded.

\section{Results and Discussion}

Since most of the animals drank very little after the first 20 -min, only the 20 -min data were analyzed. Suppression ratios were computed for experimental (no saccharin preexposure) subjects by dividing the amount of saccharin consumed by each rat on the first test day by its average daily intake over the last four baseline sessions plus its saccharin intake on the first test day. A ratio less than .5 indicates that the animal's intake of saccharin on the first test day was less than its average water intake for the last four baseline sessions, and a ratio greater than .5 indicates a larger intake of saccharin than its average water intake. The suppression ratios for the weanling, young-adult, and old-age rats were, respectively, $.63, .58$, and .53. Thus, although all age-groups' saccharin intake on the first test day was greater than their average daily intake during the last four baseline sessions, intake was age-dependent. An analysis of variance performed on these data indicated a significant between-groups effect, $\mathrm{F}(2,22)=4.56, \mathrm{p}<.025$. Individual comparisons indicated that the young adults failed to differ from both the weanling and the old-age subjects $[\operatorname{ts}(22)<1.5]$ but that the weanlings differed significantly from the old-age subjects $[t(13)=3.03, \mathrm{p}<.01]$.

These findings indicate that the older the rat, the less of a novel saccharin solution it is likely to consume relative to its normal fluid consumption. That the saccharin intake of the experimentals was greater than the average daily water intake does not indicate the absence of neophobia. Saccharin is a highly palatable substance for rats, and preference and aversion are relative to the palatability of the substance. Flavor neophobia, on the other hand, is relative to the amount that would have been consumed had the animals been familiar with the flavor. Thus, comparisons between the experimental subjects' intake (in milliliters) on the first test day and that of their respective controls would be indicative of a neophobic reaction (see Figure 1). These comparisons showed that the weanling experimental subjects failed to differ from their controls $[\mathrm{t}(14)<1.0]$, whereas both the young-adult [t(14) $=3.4, \mathrm{p}<.01]$ and old-age $[\mathrm{t}(13)=2.7, \mathrm{p}<.05] \mathrm{ex}-$

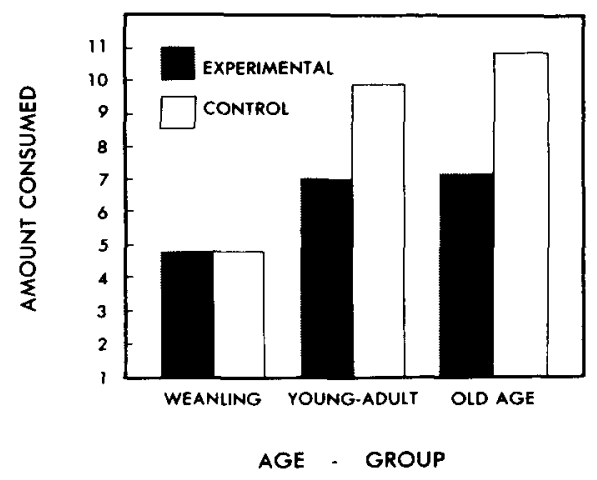

Figure 1. Amount of saccharin consumed as a function of age, hours of access, and treatment. 
perimental subjects differed significantly from their controls.

Flavor neophobia should be reduced as the animal becomes familiar with the flavor. Since the weanling rats did not show an aversion to saccharin and did not differ significantly in saccharin intake from their controls, no change in intake relative to control intake should be evident on the second test day. However, intake of both the young-adult and old-age experimental rats relative to control intake should increase, since the experimentals drank significantly less than controls on the first test day. Comparisons between experimental and control intake on the second test day indicated that the weanling and youngadult age groups failed to differ significantly from their controls [ts $(14)<1.68$ ]. The difference in intake between the old-age experimental and control animals was, however, significant $[\mathrm{t}(13)=2.14, \mathrm{p}=.05]$. Thus, a reduction of neophobia was evident in young-adult but not in old-age subjects. Similar comparisons made on the 3rd test day showed that all experimental groups failed to differ significantly from controls (ts $<1.9$ ).

These results replicate the finding of age dependency in flavor neophobia (Misanin et al., 1983) and indicate that these effects are evident along the age continuum from weaning to old age.

\section{EXPERIMENT 2}

The purpose of this experiment was to test the first prediction. The plan was to use a relatively strong US and a brief (30-min) or moderately long (3-h) preexposure to the CS-to-be. It was predicted that, with brief preexposure and a strong US, the flavor-preexposure effect would be evident only in the youngest age group. With the moderately long preexposure period, we expected a preexposure effect to be evident in the behavior of the young adults.

\section{Method}

Subjects. Ninety-six female rats of the Wistar strain, born and bred in the university animal colony, were used in this experiment. Four rats were selected from each of 24 litters. Eight litters were 21-22 days old, eight were 93-104 days old, and eight were 723733 days old at the beginning of the experiment. Littermates were housed together in standard suspended galvanized rodent cages and maintained on a 14-h-light/10-h-dark cycle. The rats had ad-lib access to food.

Apparatus. The preexposure, training, and testing sessions took place in drinking cages such as those described for Experiment 1. During all drinking sessions, the animals were housed individually, and during all drinking sessions, except the test session, the cylinders were attached to the center of the front of the cage.

Procedure. Initially, all animals were given two daily adaptation sessions, during which they had 3-h access to room-temperature tap water in the drinking cages. The littermates of each age were then assigned randomly to four groups of eight subjects each. On the day following the last adaptation session, two groups at each age level were given 3 -h access (preexposure session) to .1\% saccharin ( $w / v$ in room-temperature tap water). One of these groups received a $2 \%$ body weight ip injection of $.15 \mathrm{M} \mathrm{LiCl}$ during train- ing; the other received a comparable injection of physiological saline. Another group at each age level had 30-min access to the .1\% saccharin solution, followed immediately by 2.5 -h access to water. These groups received a $\mathrm{LiCl}$ injection during training. The fourth group at each age level had 3-h access to water during the preexposure session; this group also received a $\mathrm{LiCl}$ injection during training.

On the day following the preexposure session, training or pseudotraining took place. Taste-aversion training consisted of 10 -min access to the $.1 \%$ saccharin solution, followed by the $\mathrm{LiCl}$ injection; during pseudotraining, an injection of saline followed the 10 -min access to the saccharin solution.

The day following training and pseudotraining, all rats were given a 24-h two-bottle test (saccharin vs. water). The side on which the saccharin was presented was counterbalanced for each group. The amount of solution consumed by each subject was recorded after $.5,1,3,6,18$, and $24 \mathrm{~h}$ of access to the test solutions.

\section{Results and Discussion}

Percent preference for saccharin during the test session was computed for each rat at each access time by dividing saccharin intake to that time by the total fluid (saccharin plus water) intake and multiplying by 100 . Group percentages are depicted in Figure 2. These preference data were analyzed as a split-plot factorial (Type SPF3.46; Kirk, 1968) design. Age (weanling, young-adult, old-age) treatment (30-min-preexposed/trained, 3-h-preexposed/trained, nonpreexposed-trained, 3-h-preexposed/pseudotrained), and access time $(.5,1,3,6,18$, $24 \mathrm{~h}$ ) were the variables and their variations. This analysis yielded significant main effects of age $[F(2,21)=$ $10.32, \mathrm{p}<.001]$, treatment $[\mathrm{F}(3,63)=52.27, \mathrm{p}<$ $.001]$, and access time $[\mathrm{F}(5,105)=4.21, \mathrm{p}<.01]$. The age $\times$ access time $[\mathrm{F}(10,105)=4.31, \mathrm{p}<.001]$ and treatment $\times$ access time $[F(15,315)=1.84, p<.05]$ interactions were also significant. Planned comparisons made at the .05 level of significance indicated that preexposure reduced, but did not eliminate, taste-aversion conditioning in both preexposed-trained weanling groups. The 30-min-preexposed/trained group $[\mathrm{F}(1,63)=3.84]$ and the 3-h-preexposed/trained group $[\mathrm{F}(1,63)=15.89]$ differed significantly from the nonpreexposed-trained controls and from the pseudotrained controls $[\mathrm{Fs}(1,63)>$ 6.52]. The overall CS-preexposure effect in the 30-min

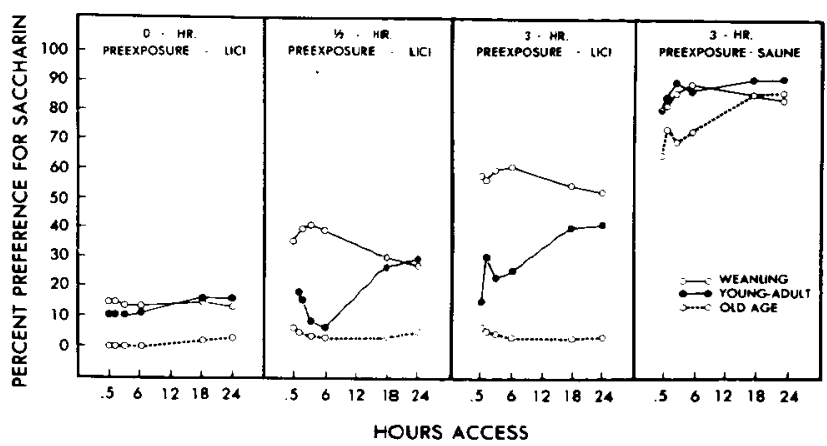

Figure 2. Percent preference for saccharin as a function of age, preexposure treatment, training treatment, and hours of access. 
preexposed weanlings, however, was due to their greater preference for saccharin at access times of $6 \mathrm{~h}$ or less; they did not differ significantly from nonpreexposedtrained controls at the 18- and 24-h access times. In contrast, overall comparisons between preexposed youngadult and old-age preexposed-trained groups and their respective nonpreexposed-trained $[\mathrm{Fs}(1,63)<2.24]$ and pseudotrained $[\mathrm{Fs}(1,63)>24.94]$ controls indicated that preexposure was ineffective in reducing taste-aversion conditioning. However, the flavor-preexposure effect was evident in the 3-h preexposed-trained young adults at the 18 - and 24-h access times [Fs $(1,504)>3.86]$. It is possible that a change in stimulus conditions resulting from the light/dark cycle hastened extinction of a weak conditioned aversion in these animals.

Comparisons of total intake (i.e., saccharin vs. saccharin plus water vs. water) of the four groups at each age level during the preexposure session showed no significant differences $[\mathrm{Fs}(3,28)<1.8, \mathrm{p}>.1]$, indicating that differences in motivation level at the time of training cannot account for differences within ages. However, comparisons of saccharin intake of the 30-min and 3-h preexposure groups at each of the age levels showed that, in all cases, the 3-h groups consumed more saccharin than the 30-min groups [ts $(14)>6.87$, ps $<.001]$, indicating that the different treatments should have led to different levels of habituation of the neophobic reaction. It is reasonable to assume, therefore, that the difference in the preexposure effect observed in the weanlings and young adults is attributable to the different levels of preexposure, that is, $30 \mathrm{~min}$ versus $3 \mathrm{~h}$. Comparison of saccharin intake of the LiCl-treated adult groups during the preexposure session indicated that the old-age rats consumed more, rather than less, saccharin than their young-adult counterparts $[F(1,28)=6.93, p<.01]$, suggesting that differences in the preexposure effect between young and old adults was due to the difficulty old-age animals have in habituating the neophobic reaction.

Our findings, then, confirm the prediction that with brief preexposure and a strong US, the flavor-preexposure effect would be evident in only the youngest age group. They also confirmed our expectation that with moderately long preexposure, age differences would be less evident. Thus, these results lend support to the notion that the flavor-preexposure effect on taste-aversion conditioning is age-dependent (Misanin et al., 1983). The relatively strong flavor-preexposure effect in weanlings, the relatively weak effect in young adults, and the failure of flavor preexposure to affect conditioning in old-age rats also lends firm support to the notion that the readiness with which flavor preexposure retards taste-aversion conditioning is inversely related to age.

There was no confirmation of or support for the prediction that taste-aversion learning should be directly related to age. Age comparisons between pseudotrained groups and between the nonpreexposed-trained groups resulted in no age effects $[\mathrm{F}(1,84)<1.44]$. This failure to confirm the fourth prediction was most likely due to ceiling and floor effects resulting, respectively, from a strong preference for saccharin at all ages and from the intense US.

\section{EXPERIMENT 3}

The purpose of this experiment was to test the second prediction. If young rats are less flavor-neophobic than adults, and if the readiness with which flavor preexposure retards conditioning is inversely related to strength of flavor neophobia in rats, then using a moderately long preexposure and a weak US during taste-aversion conditioning should reduce age differences in the flavor-preexposure effect. The plan of this experiment was, accordingly, to use the moderately long preexposure to saccharin $(3 \mathrm{~h})$ used in Experiment 2 but a weaker US ( $1 \%$ body weight injection of $.15 \mathrm{M} \mathrm{LiCl}$ ) than that used in Experiment 2 .

\section{Method}

Subjects. Twenty-four weanling (20-25 days), 24 young-adult (92-98 days), and 24 old-age ( 711 -743 days) female albino rats of the Wistar strain were used. The animals were born and reared in the university animal colony. Housing and maintenance conditions were the same as in Experiment 2, except that three like-age subjects were housed together and the light/dark cycle was suspended during the 24-h test to eliminate the possibility of a reduction in flavor aversion as a result of stimulus change. Lights remained on during the 24-h test because conditioning took place during the light phase of the light/dark cycle.

Apparatus and Procedure. Initially, the animals were given two daily 30 -min adaptation sessions, during which they had access to room-temperature tap water in the drinking cages described in Experiment 1 . At all times except during the test session, the cylinders were attached to the center of the front of the cage. The day following the second adaptation session, 16 animals at each age level were given 3-h access to a $.1 \%$ saccharin solution in the drinking cages (preexposed subjects); the remaining 8 animals at each age level had 3-h access to room-temperature tap water (nonpreexposed subjects). On the day following this preexposure session, training or pseudotraining took place. Training consisted of 10 -min access to the $.1 \%$ saccharin followed immediately by a $1 \%$ body weight ip injection of . $15 \mathrm{M} \mathrm{LiCl}$. The nonpreexposed and half of the preexposed subjects at each age level underwent training; the remaining 8 preexposed subjects at each age level underwent pseudotraining. Pseudotraining consisted of 10 -min access to the saccharin solution, followed immediately by a $1 \%$ body weight injection of physiological saline. The following day, all animals were given a two-bottle test (saccharin vs. water) with the side on which saccharin was presented counterbalanced for each group. The amount of saccharin and water consumed at access times of $.5,1,6,18$, and $24 \mathrm{~h}$ was recorded for each rat.

\section{Results and Discussion}

Depicted in Figure 3 is percent preference for saccharin during the test session. These data were analyzed as a split-plot factorial design (Type SPF-33.5), with age, treatment, and access time being the variables under consideration. This analysis yielded significant main effects of treatment $[F(2,63)=9.36, p<.001]$ and access time $[F(4,252)=9.02, p<.001]$. The age $\times$ treatment $[F(4,63)=2.66, p<.05]$ and treatment $\times$ access time 


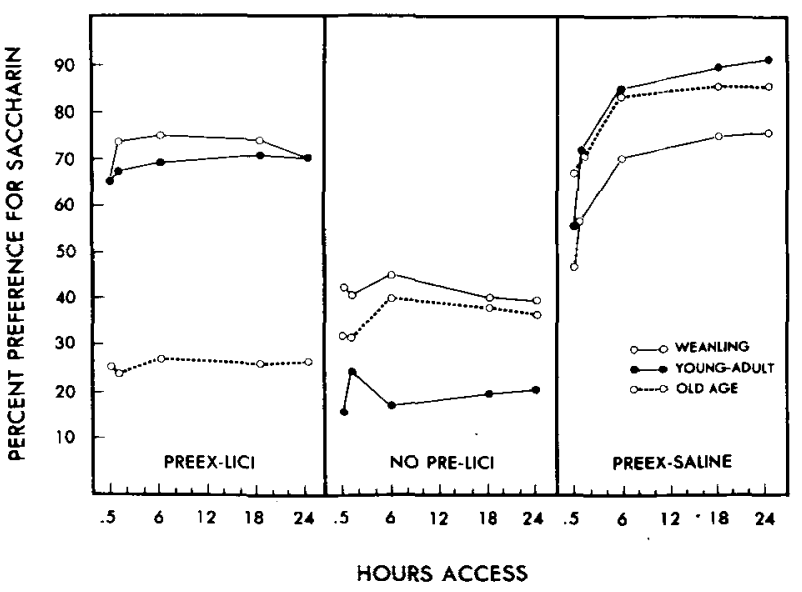

Figure 3. Percent preference for saccharin as a function of age, preexposure treatment, training treatment, and hours of access.

$[F(8,252)=3.45, \mathrm{p}<.001]$ interactions were also significant. Comparisons following the analysis of variance showed that the weanling and young-adult preexposedtrained groups (left panel, Figure 3) failed to differ significantly from their preexposed-pseudotrained controls (right panel, Figure 3 ) $[\mathrm{Fs}(1,63)<1.0]$, indicating that preexposure to the CS-to-be eliminated taste-aversion learning in these age groups. In contrast, the old-age preexposed-trained subjects (left panel, Figure 3 ) did differ significantly from their pseudotrained controls $[F(1,63)=$ $10.37, \mathrm{p}<.001]$ and failed to differ significantly from the nonpreexposed-trained controls $[F(1,63)<1.0]$, suggesting that preexposure did not even attenuate conditioned taste aversion (CTA) in these subjects. The weanling preexposed-trained animals also failed to differ from their nonpreexposed-trained controls $[F(1,63)=2.72]$. According to Misanin et al. (1983), the rapid development of "learned safety" in nonpreexposed weanlings during training can have the paradoxical effect of obscuring the CS-preexposure effect. This would be likely to occur when, as in the present experiment, the US intensity is relatively weak. However, analysis (Type CR-3) of only the weanling data showed that, over the 24-h period, the preexposed-trained weanlings did differ significantly from the nonpreexposed-trained controls $[\mathrm{Fs}(1,21)>4.20, \mathrm{p}=.05]$ and failed to differ from the pseudotrained controls $[\mathrm{Fs}(1,21)<1.0]$, indicating a significant effect of preexposure to flavor over and above any attenuating effect that flavor experience during training may have had on CTA. The attenuating effect of flavor experience during training was not sufficient to eliminate conditioning in this age group $[\mathrm{F}(1,21)=5.49, \mathrm{p}<.05]$.

Thus, these findings support the prediction that, with a moderately long preexposure and a weak US, age differences in the flavor-preexposure effect should diminish. In contrast to the results of Experiment 2, in which $3 \mathrm{~h}$ of preexposure eliminated conditioning in only weanling animals, $3 \mathrm{~h}$ of preexposure in the present experiment eliminated CTA in both weanlings and young adults.
As in Experiment 2, there was no evidence to support the fourth prediction, that the strength of taste aversion should be directly related to age. Individual comparisons showed that neither the pseudotrained (right panel, Figure 3 ) nor the nonpreexposed-trained (center panel, Figure 3) groups differed across ages $[\mathrm{Fs}(1,63)<1.98]$.

\section{EXPERIMENT 4}

The purpose of this experiment was to test the third prediction that age differences in the flavor-preexposure effect should disappear with prolonged flavor preexposure. The plan was to increase the saccharin preexposure time to $48 \mathrm{~h}$ in order to insure habituation of the neophobic reaction in rats of all ages and to use the relatively weak US of Experiment 3 so as not to counteract the effect of habituation.

\section{Method}

Subjects. Thirty-six female albino rats of the Wistar strain were used in this experiment. Twelve animals comprised each of three age groups: $21 \pm 2,160 \pm 10$, and $700 \pm 20$. The animals at each age level were randomly assigned to preexposed $(\mathrm{N}=6)$ and nonpreexposed $(\mathrm{N}=6)$ conditions. Pseudotrained controls were not used, since, in the previous experiments, they had not differed as a function of age and consistently had shown a high preference for saccharin. Like-age animals were housed in pairs (one preexposed and one nonpreexposed) with food available ad lib at all times except during the adaptation sessions. As in the previous experiment, the animals were maintained on a 14 -h-light/10-h-dark cycle that was suspended during the test session.

Apparatus. The drinking cages, cylinders, saccharin, and $\mathrm{LiCl}$ concentrations and the mode of delivery were the same as in Experiment 3.

Procedure. All animals were given two daily drinking-adaptation sessions, during which they were placed individually in the drinking cages and given 1-h access to room-temperature tap water. Twenty-three hours after these sessions, half of the animals (preexposed) at each age level were given 48 continuous hours of access to the saccharin solution; the remaining half (nonpreexposed) had $48-h$ access to water. At the end of the preexposure session, all animals were deprived of water. After $23 \mathrm{~h}$ of water deprivation, all animals were given taste-aversion training. Taste-aversion training and testing procedures were the same as those in Experiment 3.

\section{Results}

Percent preference for saccharin at each of the five access times was computed for each rat and averaged for groups. Group averages are portrayed in Figure 4. A splitplot factorial analysis of variance (Type SPF-23.5) performed on these preference data yielded a significant main effect of treatment $[F(1,30)=65.54, p<.001]$. All preexposed groups differed significantly from nonpreexposed groups $[\mathrm{Fs}(1,30)>6.30, \mathrm{p}<.001]$. There was no significant main effect of age $[F(2,30)<1.0]$. Age did, however, interact significantly with treatment $[\mathrm{F}(2,30)=$ $3.87, \mathrm{p}<.05]$. The three preexposed groups failed to differ from one another $[\operatorname{Fs}(1,30)<1.0]$, whereas the weanling nonpreexposed group differed significantly from the comparable young-adult and old-age groups $[\mathrm{Fs}(1,30)>6.07, \mathrm{p}<.001]$. The young-adult and old- 


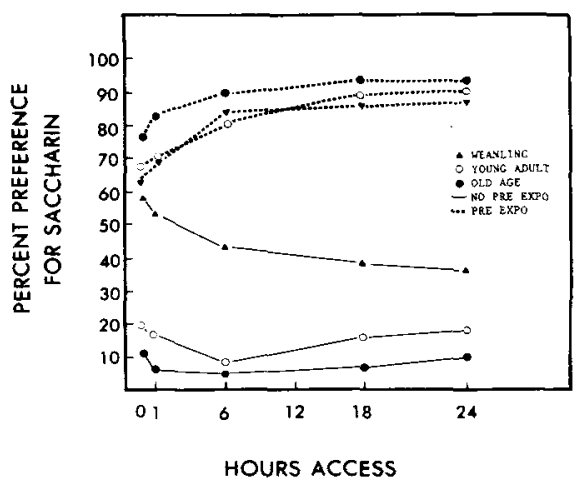

Figure 4. Percent preference for saccharin as a function of age, preexposure and training treatments, and hours of access.

age groups did not differ $[\mathrm{F}(1,30)<1.0]$. Treatment also interacted significantly with access time $[\mathrm{F}(4,120)=$ $19.16, \mathrm{p}<.001]$. Both the flavor-preexposure effect in the preexposed subjects and taste aversion in the nonpreexposed subjects tended to increase over time.

Thus, these results lend strong support to the notion (prediction 3 ) that prolonged preexposure should eliminate age differences in the flavor-preexposure effect and lend some support to the contention (prediction 4) that tasteaversion learning is directly related to age. The weanling animals in this experiment were significantly $[t(47)=$ $2.39, \mathrm{p}<.05]$ younger (mean $=22$ days) than the weanlings (mean $=23$ days) in the preceding experiment and the more rapid development of "learned safety" at this younger age level during CS presentation at training may account for the poorer CTA exhibited by weanlings in this experiment. The failure of age differences in CTA to show up in adult animals was again, we believe, due to a floor effect.

\section{EXPERIMENT 5}

The purpose of this experiment was to test the prediction that taste-aversion learning should be directly related to age. Since we believed that the failure to confirm this prediction in Experiments 2-4 was due to floor effects resulting from an intense US, our plan was to reduce US intensity. We also planned to increase the sample size so that even small differences in taste-aversion conditioning would be evident.

\section{Method}

Subjects. Forty weanling ( $20-24$ days old), 40 young-adult ( 95 107 days old), and 40 old-age (773-789 days old) female albino rats of the Wistar strain were the subjects of this experiment. They were born and reared in the university animal colony. The animals at each age level were randomly divided into experimental $(\mathrm{N}=20)$ and control $(\mathrm{N}=20)$ groups. Like-age animals were housed in pairs (one experimental and one control) and had ad-lib access to food at all times except during drinking sessions that were less than $24 \mathrm{~h}$. The animals were maintained on a 14-h-light/10-h-dark cycle except during the 24-h test during which the lights remained on.

Apparatus. The drinking cages, saccharin solution, and mode of $\mathrm{LiCl}$ injection were the same as in the previous experiments. However, a $.5 \%$ body weight injection of $.15 \mathrm{M} \mathrm{LiCl}$ served as the US.

Procedure. The animals were given five daily adaptation sessions in the drinking cages during which they had access to roomtemperature tap water. The sessions varied in length on Days 1-5 ( $2 \mathrm{~h}, 1 \mathrm{~h}, 30 \mathrm{~min}, 20 \mathrm{~min}$, and $10 \mathrm{~min}$, respectively). The day following the last adaptation session, the animals were given 10 -min access to saccharin, followed immediately by a $\mathrm{LiCl}$ injection (experimental groups) or by a comparable injection of physiological saline (control groups). The following day, they were given a 24-h two-bottle test (saccharin vs. water) in the drinking cages with food available ad lib. The amount of saccharin and water consumed after $1,6,12,18$, and $24 \mathrm{~h}$ was recorded for each rat.

\section{Results}

Percent preference for saccharin at each of the access times was computed for each rat and averaged for experimental and control groups at each age level. Group means are shown in Figure 5. These data were analyzed as a split-plot factorial (Type SPF-23.5) design, with treatment, age, and access time being the factors considered. This analysis yielded significant main effects of treatment $[F(1,114)=160.79, \mathrm{p}<.001]$, age $[\mathrm{F}(2,114)=8.49$, $\mathrm{p}<.001]$, and access time $[\mathrm{F}(4,456)=2.91, \mathrm{p}<.05]$. The age $\times$ treatment, age $\times$ access time, and treatment $x$ access time interactions were also significant (ps $<$ $.001)$. Comparisons following the analysis of variance showed that the three experimental groups differed significantly from their respective controls $[F(1,114)>$ $12.86, \mathrm{p}<.001]$, indicating taste-aversion learning at all age levels. Age comparions showed that the three control groups did not differ significantly $[F(1,114)<1.0]$, whereas the weanling experimental group differed significantly from both adult experimental groups $[\mathrm{F}(1,114)>$ $14.74, \mathrm{p}<.001]$ and the young adult experimental group differed significantly from the old-age experimentals $[F(1,114)=5.94, p<.025]$. Thus, these results confirm the prediction that CTA should be directly related to age.

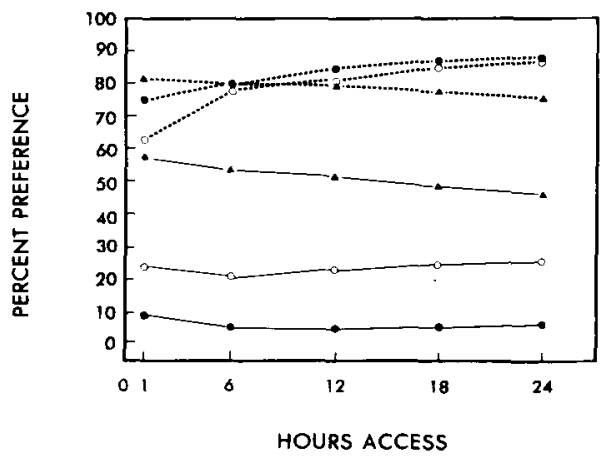

Figure 5. Percent preference for saccharin as a function of age, treatment, and hours of access. The filled circles depict the data from the old-age animals, the open circles depict the data from the young adults, and the triangles depict the data from the weanlings. The broken lines represent control data, and the solid lines represent data from experimental subjects. 


\section{GENERAL DISCUSSION}

This series of experiments provides strong support for the notion (Misanin et al., 1983) that the strength of the flavor-preexposure effect is inversely related to age and is dependent upon the initial level of flavor neophobia. Experiment 1 demonstrated that flavor neophobia is directly related to age in the rat. Old-age animals showed less preference for saccharin than did the young adults. It also took longer for flavor neophobia to habituate in old-age rats than in young adults. The young adults, in turn, showed less preference for saccharin than did the weanlings. Weanling animals, which exhibited little fear of novel flavors, showed evidence of "learned safety" after only a brief (30-min) preexposure to the flavor CS (Experiment 2), whereas young adults and old-age animals showed no evidence of "learned safety." Three hours of preexposure to the flavor CS led to "learned safety" in both weanlings and young adults but not in old-age rats (Experiment 3). With 3-h preexposure and a strong US (Experiment 2), however, young adults showed a reduction in taste aversion only after 18-h access to the flavor and during a change in the lighting conditions that had prevailed during training, suggesting a weak CS-preexposure effect. With 48-h preexposure to the flavor CS, all age groups showed what appeared to be equivalent amounts of "learned safety," although age differences may have been obscured by a ceiling effect. In any event, age differences in the flavor-preexposure effect from weanling to old age were greatly diminished with prolonged flavor preexposure.

We hypothesized that just as it is difficult to convert a feared stimulus into a safety signal, it should be difficult to convert a safe stimulus into a feared stimulus. This hypothesis led to the unlikely prediction that old-age animals would show the strongest taste-aversion conditioning since flavor neophobia was found to be stronger in old-age animals than in young-adult and weanling rats. Experiment 5 demonstrated this to be so.

Although this series of experiments lends support to the hypothesis that the flavor-CS preexposure effect is dependent upon the strength of flavor neophobia, it is not closed to other interpretations. Wagner (1978) has proposed an interpretation of the CS-preexposure effect that is devoid of the subjectivity implied in "learned safety." His interpretation is based on the premise (p. 178) that if an environmental event (e.g., a CS-to-be), is prerepresented in short-term memory by the retrieval action of cues (e.g., contextual cues) with which it had previously been associated, then it will be less likely to be rehearsed and, hence, less likely than events not so represented to enter into an association with other environmental events (e.g., US). During CS preexposure, the animal may form an association between the CS-to-be and the context in which it appears. Thus, during training, the context primes a representation of the CS in shortterm memory and, consequently, the CS and US are less likely to become associated. Hence, conditioning is re- tarded. If we assume that the ease with which the rat associates flavor with the drinking-cage context is inversely related to age, then the results of Experiments 2-4 conform to Wagner's interpretation of the CS-preexposure effect. This assumption is not an unreasonable one. Oldage animals who have been living for 2 years or more in cages resembling the drinking cages may attend little to the contextual cues if preexposure is brief and other novel stimuli, that is, flavor stimuli, are present, whereas weanling rats who have been living in the nest may be as attentive to the novel cage environment as they are to novel flavors.

The results of Experiments 1 and 5 can also be explained by age differences in response to contextual stimuli. Mitchell, Winter, and Moffitt (1980) have shown that context habituation enhances flavor neophobia and conditioned taste aversion. They gave groups of rats 5 or 30 days' exposure to the test environment prior to pairing $\mathrm{LiCl}$ or saline with saccharin or water, and found that animals habituated to the test environment for $\mathbf{3 0}$ days showed a stronger CTA and more flavor neophobia than animals exposed to the test environment for only 5 days. These investigators suggested that context habituation alters the relative novelty of the flavor stimulus, and that relative novelty is an important determinant of conditioned taste aversion and flavor neophobia. Greater relative novelty leads to more intense flavor neophobia and stronger conditioned taste aversion. In our study, the relative novelty of saccharin would have been greatest for oldage rats who had spent nearly 2 years in an environment similar to the test environment and least for weanlings who had experienced an environment similar to the test environment only during the experimental session.

Our lack of neophobia in weanling rats appears to disagree with Gemberling, Domjan, and Amsel's (1980) finding of flavor neophobia in 5-day-old rats. Procedural differences, however, may account for this discrepancy. In the Gemberling et al. study, rat pups were subjected to oral infusion of the novel-flavored solution, whereas the weanlings in the present study experienced the novel flavor in a free-choice situation. Thus, as suggested by Misanin et al. (1983), it is possible that latent fear responses in young rats emerge if the young rats are forced to confront a potentially dangerous stimulus, whereas they may fail to emerge in a free-choice situation.

Our results also appear at odds with a growing body of data being interpreted as indicating the "independence" (Braveman \& Jarvis, 1978) or "decoupling" (Miller \& Holzman, 1981) of flavor neophobia and conditioned taste aversion. These investigators have shown that familiarization procedures that reduce neophobia can leave CTA unaltered. Judging from the results of our experiments, these investigators used what may be considered rather intense US, . $75 \%-1 \%$ body weight injections of $.3 \mathrm{M} \mathrm{LiCl}$. Reliable differences in CTA associated with differences in neophobia became apparent in the present series of experiments only when the intensity of the US was reduced to a $.5 \%$ body weight injection of .15M LiCl. Apparently, 
US intensity is a factor that can obscure or override the contribution of neophobia to conditioned taste aversion. Thus, had US intensity been less or preexposure duration greater in the Braveman-Jarvis and Miller-Holzman studies, the attenuating effect of preexposure on conditioning and, hence, the contribution of neophobia to CTA would have been evident. In fact, Tarpy and McIntosh (1977) had previously shown that the familiarization procedure used by Braveman and Jarvis (1978) and Miller and Holzman (1981) to reduce neophobia also alters CTA if familiarization is extensive. Thus, it would appear that unlearned fear of novel flavors is, in most cases, simply weaker than conditioned fear and, hence, is altered more easily than CTA by factors that influence fear.

Bitterman (1965), examining phylogenetic differences in learning, described an approach he called control by systematic variation. Acknowledging the difficulty in equating motivational, sensory, motor, and other performance variables for widely divergent species, Bitterman noted that careful and judicious variation of these factors along the line of a specific hypothesis might allow investigators to determine functional relations among various species. We believe that this approach of control by systematic variation deserves as much attention when examining ontogenetic differences as does the approach of systematically varying the assessment task (e.g., Ampuero \& Campbell, 1983; Hoffman, Misanin, \& Hinderliter, 1984; Rudy, Vogt, \& Hyson, 1983). Many of the problems inherent in phylogenetic comparisons are apparent when making age comparisons. Thus, systematic variation may help to more fully describe critical ontogenetic differences. For example, in the present study, age differences in conditioned taste aversion appeared in nonpreexposed animals only when the intensity of the US was varied from very strong (Experiment 2 ) to very weak (Experiment 5). Similarly, by varying the duration of saccharin preexposure in Experiments 2-4, we were able to either diminish or exaggerate age differences in "learned safety." Thus, systematic parametric variation is not only helpful in understanding ontogenetic differences, but is necessary for obtaining an accurate description of how such processes as learning change with age.

\section{REFERENCES}

Ampuero, M. S., \& CAMpbell, B. A. (1983, April). Ontogeny of the conditioned heart rate response to tone-shock pairings in the rat. Paper presented at the Eastern Psychological Association, Philadelphia.

BAKer, L. J., BAKER, T. B., \& KeSNER, R. P. (1977). Taste aversion learning in young and adult rats. Journal of Comparative and Physiological Psychology, 91, 1168-1178.

Bitterman, M. E. (1965). Phyletic difference in learning. American Psychologist, 20, 396-410.

BRAVEMAN, N. S., \& JARVIS, P. S. (1978). Independence of neophobia and taste aversion learning. Animal Learning \& Behavior, 6, 406-412.

Gemberling, G. A., Domuan, M., \& AMSEL, A. (1980). Aversion learning in 5-day-old rats: Taste-toxicosis and texture-shock associations. Journal of Comparative and Physiological Psychology, 94, 734-745.

Hoffman, B. A., Misanin, J. R., \& Hinderliter, C. F. (1984). Age differences in the active avoidance learning of preweanling rats. Psychological Record, 34, 149-155.

Kalat, J. W., Rozin, P. (1973). "Learned safety" as a mechanism in long-delay taste-aversion learning in rats. Journal of Comparative and Physiological Psychology, 83, 198-207.

KIRK, R. E. (1968). Experimental design: Procedures for the behavioral sciences. Belmont, CA: Brooks/Cole.

LuBow, R. E. (1973). Latent inhibition. Psychological Bulletin, 79, 398-407.

Lubow, R. E., \& Moore, A. U. (1959). Latent inhibition: The effect of nonreinforced pre-exposure to the conditioning stimulus. Journal of Comparative and Physiological Psychology, 52, 415-419.

Martin, G. N., \& Timmins, W. K. (1980). Taste-sickness associations in young rats over varying delays, stimulus, and test conditions. Animal Learning \& Behavior, 8, 529-533.

Miller, R. R., \& Holzman, A. D. (1981). Neophobias and conditioned taste aversions in rats following exposure to novel flavors. Animal Learning \& Behavior, 9, 89-100.

Misanin, J. R., Guanowsky, V., \& Riccio, D. C. (1983). The effect of CS-preexposure on conditioned taste aversion in young and adult rats. Physiology \& Behavior, 30, 859-862.

Mitchell, D., Winter, W., \& MoffitT, T. (1980). Cross-modality contrast: Exteroceptive context habituation enhances taste neophobia and conditioned taste aversions. Animal Learning \& Behavior, 8, 524-528.

Rudy, J. W., Vogr, M. B., \& HYson, R. L. (1983). A developmental analysis of the rat's learned reactions to gustatory and auditory stimulation. In R. Krail \& N. E. Spear (Eds.), Comparative perspectives on memory development (pp. 1-40). Hillsdale, NJ: Erlbaum.

TARPY, R. M., \& MCINTOSH, S. M. (1977). Generalized latent inhibition in taste-aversion learning. Bulletin of the Psychonomic Society, 10, 379-381.

WAGNER, A. R. (1978). Expectancies in the priming of STM. In S. H. Hulse, H. Fowler, \& W. K. Honig (Eds.), Cognitive process in animal behavior (pp. 177-209). Hillsdale, NJ: Erlbaum.

(Manuscript received July 9, 1984;

revision accepted for publication December 21,1984 .) 